\title{
Risks and Vulnerabilities in Resettlement Induced by Highway Construction Project: A Case of Southern Transport Development Project in Sri Lanka
}

\author{
So Morikawa
}

\begin{abstract}
Building on previous resettlement models, we studied risks and vulnerabilities in resettlement process induced by the first highway development project in Sri Lanka: Southern Transport Development Project (STDP). In this paper, we report the results of the analysis on descriptive answers to questions about risks of Affected People (APs) in our interview survey. From the viewpoint of APs' satisfaction, resettlement in STDP can be evaluated as successful resettlement, but from their answers we could observe several risks and vulnerabilities on income sources and social networks. In addition, we found that relative deprivation is an important hindrance to community integration in the new environment. We noted that flexible interpretations of vulnerability by relevant officers are necessary.
\end{abstract}

Index Terms-Land acquisition, development-induced resettlement, resettlement risks, vulnerability.

\section{INTRODUCTION}

Many infrastructural projects including roads and railways in developing countries are generally socially beneficial; but their construction often causes large scale of displacement and resettlement of persons and communities. According to Cernea, during 1990s about 1 million people were resettled because of infrastructural development projects. This number well exceeds the number of people resettled because of wars or natural disasters [1]. Not only displacement and resettlement deprives the affected people (APs) of their accustomed way of life. Often resettlement sites are established on land of poor quality, and as a result, in such locations they cannot earn their livelihood. It is also difficult to find job opportunities to sustain their income and their lifestyle. Because displacement and resettlement seriously affect people economically, socially, culturally, physically and psychologically, people and NGOs oppose many development projects. The main reason for such opposition and resistance is land acquisition which makes them impoverished and socially marginalized. However, in some development projects, because the government place high priority on project implementation schedule, the land acquisition sometimes take ruthless and violent form and sometimes end up without paying any

Manuscript received July 15, 2017; revised September 10, 2017. This study is based on the author's Master's thesis submitted to Department of Civil Engineering, the University of Tokyo in March 2011 and was supported until now by JSPS KAKENHI Grant Numbers 13J07950, 26885017, 16K17046.

So Morikawa is with Department of Civil Engineering, the University of Tokyo, Tokyo, Japan (e-mail: Morikawa@civil.t.u-tokyo.ac.jp). compensation for acquiring land and other property [1].

Such cases of land acquisition and resettlement adversely affect not only the project concerned, but also future projects, as sustained pressure from citizens and NGOs to reconsider project design and the frequent tensions between APs and their communities and project authorities create a bad image of land acquisition and resettlement policy among such people and their communities.

For government officials and donor agencies, the displacement and resettlement phase in the project cycle is an extremely stressful phase which could lead to outbreak of troubles in project areas. Although resettlement or social safeguard staffs at donor agencies are expected to help easing the problems or conflicts, they often find that their role is not much appreciated by executing agencies. Rather, they often get cold treatment from both project staffs and APs. This is because the guidelines the donor agencies formulate to guide the resettlement processes are considered to be another troublesome process added to the already complicated project process. Facing the mountain of documents already piled up at the offices and limited resources such agencies have to process resettlement, advices to government officials or APs can be seen as a mere meddlesome intervention in their business.

Some sociologists and anthropologists therefore suggest a way to overcome the above tensions and incompatibility between development agencies and communities. They recommend that the resettlement should be presented as a development opportunity for APs, by giving priority to them in sharing project revenues. According to them, what should be given to APs for the price of their losses are not only compensation, but also longer-term development funds and partial ownership of the project and its benefits.

Building on previous resettlement models, we studied the first highway development project in Sri Lanka: Southern Transport Development Project (STDP). In this paper, we report the results of the analysis on descriptive answers to our interview questions about APs' risks. First, we review models of resettlement process and risks in the next section. The third section explains our case and interviews we conducted and the following section shows our results. The final section concludes our discussion.

\section{Models of ResettLement Process AND Risks}

\section{A. Scudder's Four Stage Framework [2]}

Thayler Scudder, who has long been studying dam 
construction-induced resettlement, presented his Four Stage Framework in 1980s "to deal exclusively with a successful process of involuntary resettlement in connection with dam construction" [2].

According to the framework, dam construction-induced resettlement consists of four stages along with the timeline of the project cycle: Planning and Recruitment; Adjustment and Coping; Community Formation and Economic Development; and Handing Over and Incorporation. Planning and Recruitment (Stage 1) is preparatory stage of the project, in which the resettlement has not been commenced yet. He explains APs' anxiety increases as the resettlement becomes near event, but "increased involvement in the planning process will reduce, but not eliminate, the stress" [2].

In next two stages, he emphasizes the change of APs' "risk" attitude, the point on which I want to focus in this study. In the stage of Adjustment and Coping (Stage 2), which covers several years on and after the resettlement, he describes "the behavior of the majority tends to risk averse and their living standards can be expected to drop" (ibid. 32). Meanwhile, in the stage of Community Formation and Economic Development (Stage 3), which is the most essential to see whether the resettlement is successful, he says "risk-taking occurs and the majority of resettlers are able to improve their living standards", and this is how the development of APs is achieved [2].

The final stage of Handing Over and Incorporation (Stage 4) depicts the phase in which the managing authority is handed over from project authority to existing ministries or resettlers' and hosts' organization and the second generation of the resettlers succeed the whole legacy of the project from their parents' generation [2].

Since follow-up studies are terminated several years after the construction in the longest, this model contributed to make practitioners alert themselves of long-term effects of the project, which includes two generations especially in Stage 3 and 4.

\section{B. Cernea's Impoverishment Risks and Reconstruction (IRR) Model [1]}

Scudder's Four Stage Framework compounded in 1980s received constructive criticism toward the end of that decade. To overcome these deficits in previous models, Michael Cernea, who is a social scientist with sociological background, constructed impoverishment risks and (livelihood) reconstruction (IRR) model in 1990s [1]. His model was designed to be diagnostic -explanatory and cognitive- and predictive -warning and planning, and to have both problem solving function and research function [1]. Important background of constructing this model was his doubts on cost-benefit analysis and cash compensation, both of which were based on one economic principle: Compensation Principle. Cernea believed that those who use this principle to evaluate resettlement performance could underestimate the cost of the project and tend to urge an enterprise which is in fact causes impoverishment of APs rather than their development.

His model was composed of eight categories of risks, which APs will commonly face with: landlessness, joblessness, homelessness, marginalization, increased morbidity and mortality, food security, loss of access to common property and social disarticulation. He also mentioned the timing and the duration in the project cycle for each risk.

Describing these eight risks, Cernea insists that understanding of these risks, which he called prophecy of the model, enable executing agencies and APs to prepare for facing the risks or to negotiation among actors to eliminate or minimize the risks, and accordingly this model serves as self-destroying prophecies [1]. For example, in order to turn the risks of landlessness and joblessness in to land-based reestablishment and reemployment, successful approaches are used like "identifying equivalent lands, or bringing new lands into production through land recovery, crop intensification or shift to more valuable crops, diversification of on-farm/off-farm activities, use of project-created resources such as reservoirs, irrigated areas downstream, new employment, etc." [1].

In this sense, although he denies project benefits calculated on Compensation Principle, but he does not think all of the projects harm the people; rather, he thinks some projects can have the chance of development of the region. He gave policy examples such as funds for regional development using the share of the project revenue, shift to more valuable crops and diversification of the agricultural crops and shift from dependence on agriculture to fishery, of which the project gives the opportunity to APs [3].

\section{Empirical Development}

As the trends in practice moves "from restoring the lost income back to the state before resettlement, to further development of the livelihoods of affected people above the baseline, through investment" [4], not only impact assessment of resettlement but APs' livelihood adaptation has been acquiring more and more attentions in empirical studies, one whose interests is determinants of APs' coping strategies. Reference [4], for example, studies this issue referring to the livelihood perspectives, "where assets are considered as main indicators of household capability to cope with stress and shocks and are thus key determinants of their strategies to seek livelihood security" [4]. It investigate significance of four types of assets, human capital, social capital, financial capital, and natural capital but excludes physical capital.

While much of the works from such viewpoints has been done especially on dam-induced resettlement in the development context [1], [4] and on adaptations to climate change [5] (and climate-change induced resettlement [6]) out of that context, this paper aims to contribute to this scholarly works in the highway construction context. While same as studies in other contexts, income sources should be looked at, we will emphasize social capital and physical capital are also important in this context. 


\section{OUR STUDY}

Our target case, Southern Transport Development Project (STDP) is the first controlled access expressway construction project in Sri Lanka, funded by Asian Development Bank (ADB) and Japan Bank for International Cooperation (JBIC). A $126 \mathrm{~km}$-length highway was constructed and now is being operating from Kottawa, which is on the outskirt of the Colombo, to Matara in the Southern part of the island. The project Executing Agency (EA) was Road Development Authority (RDA) that was organized under the Ministry of Highways, Ports and Shipping (at present the Ministry of Highways and Investment Promotion).

Although the project had some problems so that it was brought into the court and ADB's Compliance Review Panel, STDP is highly evaluated because it built a unique Grievance Redress Mechanism, which listened to APs' voices carefully and absorb their complaints through appropriate measures. Nevertheless, even if EA tries to conduct dialogues with APs, they are not always implemented properly because of the lack of its institutional capacity or APs' distrust of government and EA. This sometimes causes APs' opposition to such mechanisms. Therefore, we should not regard frequent dialogues with APs or APs' active participation themselves as a successful factor of STDP.

In this regard, noting that well-known STDP should be a good case to see the APs' perceptions and risks they faced, I conducted interview and questionnaire survey to 128 affected households and 14 staffs in EA and ADB in my two 1 month visits to Sri Lanka in September to October 2010 and in December 2010 to January 2011.

For affected households, a questionnaire is prepared to analyze risk perception of APs and perceptions on the resettlement and the project. One interview took 2 hours on average. While we reported results of our quantitative analysis in another paper [7], we focus in this paper on the results of our analysis on descriptive questions below (in part 6 in our questionnaire):

1) What are economic impacts of STDP on your income source? (6-a)

2) What are social impacts of STDP on your income source? (6-b)

3) What change has STDP generated in social network around you? (6-c)

4) What adverse/positive impacts has STDP generated in your life? (6-d)

For staff interviews, we met 14 staffs raging from the management level of the project to the field officers including Resettlement Officers (ROs) and Assistants (RAs). In the interviews, we discussed the results of AP interviews and heard their views and interpretations on them. For instance, we asked what kind of people they think are most vulnerable to the resettlement risks and which risks they think are the most serious for APs.

\section{RESULTS}

\section{A. Satisfaction with STDP and Its General Impacts}

From the viewpoint of APs' satisfaction, resettlement in
STDP can be evaluated as successful resettlement. Table I shows the distribution of APs' satisfaction with STDP evaluated from 1 (unsatisfied) to 5 (satisfied). Though some people complained of some modules of the project like compensation and staffs, most of the APs evaluated STDP as 3 (neutral) or higher.

TABLE I: DISTRIBUTION OF APS' SATISFACTION WITH STDP

\begin{tabular}{ccccc}
\hline \hline $\begin{array}{c}1 \\
\text { (unsatisfied) }\end{array}$ & 2 & 3 & 4 & 5 \\
\hline 7 & 5 & 21 & 14 & 81 \\
$(5.5 \%)$ & $(3.9 \%)$ & $(16.4 \%)$ & $(10.9 \%)$ & $(63.3 \%)$ \\
\hline \hline
\end{tabular}

It was impressive for the author that even the households who expressed many complaints gave high evaluation of the project for the reason of national development or development for children's generation. The fact that APs understand the need for road development as a mean of national development was one important basis of the success of STDP resettlement. At the same time, we interpreted that it also means that APs' livelihood has been restored at least by minimum level.

When we ask "What adverse/positive impacts has STDP generated in your life?" (6-d), the most popular answer for positive impacts was that they could build a better house as a positive impact of STDP. The improvements of access to transportation like roads and buses; the improvement of access to the cities; and the acquisition of electricity services were often well mentioned. Note that some families expressed that they were deprived of the access to transportation and cities by STDP.

For adverse impacts, there were a wide variety of responses. Among them, income losses and the deterioration of the quality or quantity of water are often mentioned. Many households complained about the change that they had to buy what they could have cultivated in their home gardens like coconut and jack because the trees were affected. Risks of food and nutrition have also mentioned in dam-construction contexts as an expansion of environmental impacts on ecological system [8].

As for some specific descriptions in the context of highway construction, security problems are also often mentioned, on which we describe later in detail, especially among self-relocated people. Complaints about construction related adverse impacts like noise or vibration were also reported often. As is expressed in the comment "Most of the officers have come and have asked to sign for many documents without explaining." (HH M08), some people felt annoying with the acquisition and resettlement staffs.

\section{B. Risks and Vulnerabilities on Income Sources}

For answers to the question "What are economic impacts of STDP on your income source?" (6-a), income loss from paddy land or tea estate and loss of self-cultivated goods like coconut and jack are often mentioned. Here, we discuss 'overlooked' vulnerability: occupational vulnerability. We explain each occupational category below, but generally people who engage in land-independent occupations like carpenters answered that there was no impacts on income compared to 
people who engage in land-depended occupations like agriculture or shops.

\section{Agriculture}

Livelihood of agricultural households depends on land. When the land was acquired and the income was lost or reduced, but that lost or reduction had not yet recovered by other income sources, such households have high risks for the future.

In the case where they recovered their income, the recovery owes to their own effort or adaptive capacity. We can compare Household (HH) M15 and HH L13 to see how the dependence on agricultural income raises the risk of resettlement. On one hand, HH M15's household head worked in a tea estate before resettlement, so he had to change his job to a driver. Facing such a big risk, he could not attain a good image on STDP. He said "We lost income opportunities. When we faced difficulties we felt STDP was a devil." On the other hand, $\mathrm{HH}$ L13 already had an income as a driver apart from the income from a tea estate. Therefore, HH L13 succeeded to recover their image on the resettlement or the project.

\section{Laborers}

In general, households whose members had to change their occupations are considered to be the most vulnerable because it is no easy to find new jobs in the new environment. Especially, laborers depend their work on their local networks, which are easily lost by the project. Accordingly, they faced big job/income risks, pointing out the difficulty in finding a job in their new environment, where job-finding networks in the previous place do not work. "Income reduced. Earlier, I did some laborer works, but in new area, it is difficult to find jobs easily. (HH 32)"; "In the past, there are more chances to do labor job. But now we have a new place, so we have more difficulties to find a job. (HH131)"; "Before, I had good social connection, so I had so many works. Now the majority is new and people do not know about me, so I am lack of my works. (HH125)"

In case of STDP, the recovery of the jobs was made by themselves. Fortunately, most of the families we visited in our survey could find new jobs in the new environment. HH 30 and $\mathrm{HH} 32$ had to lose the previous job because of the resettlement, but they could find new jobs after the resettlement. Moreover, they succeeded to increase the income, so now they highly evaluate the project seeing that they could build a better house.

\section{Drivers, Carpenters and Shopkeepers}

Shopkeepers are considered to be easily affected because location and accessibility of the stores and networks with their local customers are critical for their business. HH 13, HH 28 and HH L28 mentioned the decrease of the shop income.

For carpenter households, whether they could maintain the customers' network after the resettlement is the key factor of deciding their risk vulnerability. For example, HH M02a said "The opportunities of work (as a carpenter) reduced as the most of known people had to go away from the area", and $\mathrm{HH}$ 28 (the respondent's husband is a carpenter) pointed out the loss of network of customers as well as the decrease of the income from her furniture showroom. Meanwhile, we can find answers like "I didn't lose income opportunities as I work as a carpenter before and now! (HH 29)", "No (economic impact on my income source) because I am a carpenter. (HH 02)", or "Mason job is not disturbed (by STDP). (HH 54)"

\section{Workers for Companies or the Government}

When family members work for companies or the government, they did not need to change their jobs or working places. Therefore, they are considered to be less vulnerable than people who engage in other occupations.

\section{Risks and Vulnerabilities on Social Networks}

For the question "What are social impacts of STDP around you?" (6-b), "not any special" answers were found in 62 households (48\%), and it was interesting to see many households answered that social network is good or even better in the question "What change has STDP generated in social network around you?" (6-c).

Among their reasons, the dominant one is they got little social impact because they moved to near place from their original lands. Meanwhile, most of the people who answered that they observed some social impacts mentioned the divide of the networks of relatives and neighbors. HH 62 answered that "Family connection was broken. Now wife lives separately."

Cernea emphasizes the segmentation risk when he discusses risk for social networks [1]. In fact, we heard many descriptions of destruction of the relationship among neighbors or relatives. For instance, HH M02a said "Parents are in the other side of the road. It is difficult to reach them always." and HH M16 said "The people who were around since childhood spread everywhere."

Also, we met some cases where one village was divided or some households in one village had to move and be separated from their original communities. For, instance, HH L20 said "Due to STDP, the village was divided into two and social relationships reduced." and HH M29 said "Some neighbors had to move from the village so the connections with them have reduced."

Some households find some difficulties in coping with new neighbors and responses are related to the relationship between people from other villages. For example, in one resettlement site, where some villagers got together in the site, HH 32 said "We have connections only with the people came from our original village." And in the same site, regarding common property, HH 31 answered that "We have to bath using a common well. So girls face difficulties from the boys from other villages." HH 29 reasoned these problems saying that they have some problems in the social network because the site originated from 5 different villages. Likewise, $\mathrm{HH}$ M04 said "Due to the deviation from the original society, it is difficult to live with the neighbors who live around. Some people are not matching with us."

Though it is possible to interpret such problems as personal ones, we have to note that they could be connected to social background like caste. When a small number of lower caste households move to the area where the others are in higher caste, it is very difficult to build a relationship with neighbors. As HH 24 said "Neighbors are not good. Whatever the 
incident or programs or some sort of donations given, they are neglected from the village as we belongs to low cast." the existence of caste is hindering the integration of host village and resettlers. In fact, in his resettlement site, people graded social network problems in higher rank than in other resettlement sites. HH 25 also answered to the question 6-b, which is about STDP's social impact, "Difficulty with being with people from various castes". Despite no mention on caste, HH 26 said "Relative and social relations are weak, and as the neighbors are different from our original place, we need to build a new relationship."

Self-relocated people, who decided not to reside in government provided resettlement sites, also referred to caste-originated problems. HH M26 gave "host village people of high caste" as a problem of solidarity among residents and said "Some people in the present village do not consider us equally. By telling about the cast, they neglect us. Only 3 or 4 families are acquaintance."

HH 78 once had moved to one resettlement site and had been satisfied with big, new house with electricity. However, in addition to financial reason and social network problem made them to go back to their original narrow land between the river side the highway. They answered in question 6-b. that "People do not like us to stay at the resettlement site."

The size of resettlement sites also seems an important factor to prevent risks for social networks. We found one example, where only 4 households are living and the size is too small to make a new network among residents. Though STDP staffs sometimes emphasized that they prepared special resettlement sites for the small number of households (even they have a resettlement site which includes only one household), which we admit is usually good, we have to prevent the situation where EA put too much emphasis on nearness of the resettlement site and the original site and as a result APs bear risks for social networks.

Not only the destruction of social networks is by itself APs' risk, but our survey results reveal that it generates further risks. Especially, risks on security are generally recognized by APs, which were not mentioned well in resettlement studies and key informant interviews. According to the interviews, there are mainly two ways security risks are generated. One is security risk when they have to be away from the house rise. For example, HH27 mentioned that relatives and acquaintances, who APs could ask to see their house when they are out, are not near. The other is security risks which come to be recognized because of distrust among neighbors. We heard about distrust among neighbors from more families than we expected. For example, HH 29 said "People around the house are not good although some are good." and HH 30 also answered that "Safety is a big concern because bad people are living here." In such cases, although there are few crimes in reality, the distrust could incline them to anxiety. $\mathrm{HH} 28$ told us the experience that they were suspected to be taking agricultural crops from a neighbor household, who owns the land but not lives there.

In addition to these two processes, some households pointed out the change of people's attitude after receiving the compensation. "When people get a large amount of money at once, they became different and behave like superior powers of the society and people have used to give briberies to make any work done. (HH M01)"; "After STDP, people in village have become very much selfish and relationships also depend on economical manner. (HH M09)"

Security risks are worth emphasizing especially in road development induced resettlement because a road itself can raise security risks by the following two ways. First, robberies which take advantage of good access of the expressway. $\mathrm{HH}$ M02a pointed out that the construction of expressway increased robberies because they can escape very fast through newly constructed expressway. HH M21 also said "As the road is nearby, strangers can easily access." Second, problems caused or would be caused by workers. Other than mentioning bad deeds of STDP workers such as "Most of the workers steal fuel, material and so on." (HH29, M17), HH 02b said STDP workers came to their houses to drink water or to use washroom. By doing that, they can know what APs living near the expressway possess, and the respondent is anxious that after the construction, the workers lose their jobs and become robberies using the locality they acquired when they worked in the area.

\section{Relative Deprivation}

It is worth noting the importance of relative deprivation in APs' perceptions. One resettlement site is built on flat land, which means that geographical condition of this site is relatively good. However, because some people in the resettlement site got 20 perch land and the other only got 10 perch land, especially the latter are feeling unfair to the former. HH 29, which received 20 perch land pointed out this aspect and said "Though the resettlement site is very good, one problem is social network." Overall evaluation of the seriousness of the problems on social networks is higher than in other resettlement sites.

Ill-understanding of the compensation scheme is one cause of the problem. Though $\mathrm{HH} 30$ asserted that it is unfair to be given different amount of land according to the timing of resettlement, RDA staffs explained that the difference only reflects the original status of land ownership: they gave a 20 perch land for those who had legal land ownership and a 10 perch land for those who did not have one. Some people seem to misunderstand because the difference of the timing of resettlement accidentally corresponds to the difference of ownership status.

The placement of 20 perch land and 10 perch land also might have strengthened the problem. 20 perch households and 10 perch households are clearly divided in two areas in the resettlement site. We interviewed with the families on both side of the road which divides two areas, and they answered that there are no connection with "the other side of the road". HH 32, which is 10 perch households, answered that "We only have a social network with 3 households and we have a safety problem because there are bad people in this site."

The importance of the "relative difference" seems to be not limited to the difference among the absolute amounts of land 
they received as we can see in the previous case. According to the interview with one RO, in another resettlement site, though they are given the same amount of land ( 20 perches), as their original lands were different in their spread, the people who had big land feel unfair to see the others who had smaller land go the same amount of land.

Furthermore, though in STDP the lots are allocated to each household by using a lottery, which means that layout of neighbor households are NOT preserved in this project, in this resettlement site the layout was preserved by accident, which provided the environment where the friction among residents easily occur. Usually, preserving the layout of neighbor households is considered to be preferable in resettlement, but when we see the similar arrangement of neighbors could lead to the friction among residents like in this case, we can see EA has to be flexible on this principle.

We also found other "sources" of relative deprivation yielding dissatisfaction with the project. First, difference between owners and renters: For example, HH 10 owned only 20 perch land but cultivated 300 perch paddy land as a renter. This paddy land was fully affected by the project and its compensation has all gone to the owner. One interviewee pointed out that though statutory value has to be paid to the owner according to the law, RDA sometimes arranges to pay LARC compensation to renters.

Failure to receive the compensation amount the officers declared and difference between early comers and late comers are also raised as reasons of dissatisfaction with the project. $\mathrm{HH} 30$ is unsatisfied with the compensation because they could not get the amount the government declared at the beginning. Also, HH M01 said that "because of the fact that officers have not done what they had said and also because we found that later other people got better compensation for the same condition than us," the image got worse. The fact that there are some unfair difference between people who resettled earlier and those who came later was also admitted by a public official himself. It was partly conducted as a strategy to promote early resettlement.

\section{CONCLUDING REMARKS}

Our survey results confirm that STDP resettlement was successful in that many APs are satisfied with the project and improved their perceptions on the project. From answers to our questions in the interviews, we could identify three factors which influence APs' overall satisfaction with the project: i) restoration or improvement of livelihood, ii) adaptation to the new environment and iii) success of some resettlement policies.

In i) restoration or improvement of livelihood, a bigger house than before bought with compensation money or new income resources (sometimes acquired by children's generation) played an important role. Though APs' ii) adaptation to the new environment was achieved mainly on their own effort in STDP, iii) some resettlement policies succeeded in making the new environment better than APs had expected. Non-monetary compensation like land deeds, electricity and road access was successful in promoting acceptance and improvement of the image of the project.

Monetary compensation is easy way as a compensation method, but it is broadly recognized that it is not enough to "give APs compensation for the damage" to restore their livelihood. It is said that we could not sum up all the damages and lost opportunities into monetary loss. And once compensation is given to people, people often cannot use it in good manner considering their future even if it is originally enough to restore their livelihood. Also, unclear criteria for evaluation of compensation invite APs' feeling of unfairness partly because the given amount is too clear. Meanwhile, non-monetary compensation like giving land (title) can directly satisfy APs' needs in their lives.

Nevertheless, I would like to emphasize we cannot give the same thing and environment for all of what APs lost. Of course, we should do our best to achieve as much as possible. However, though land to land compensation is often recommended, many difficulties of its implementation are often mentioned by field officers and income restoration programs implemented along resettlement are often found to have little contribution to getting jobs. These failures are somewhat very 'natural' because a project and its following resettlement rarely yield alternative land and good permanent jobs APs want.

As we have seen, APs' acceptance of the resettlement needs their adaptation and their effort toward it very much. Both monetary compensation and too idealistic non-monetary compensation is not the best solution because it can give little support for their effort towards adaptation to the new environment. What needed are resettlement and compensation policies which support their effort towards adaptation and building and keeping social network. Social network is important because they can find useful information to restore their livelihood like job opportunities.

To implement such policies, flexible reactions to each affected household' situation is necessary. In STDP case, RO and RA succeeded in making the basis of flexible management. They can succeed in explaining the project and the procedure of land acquisition and resettlement by visiting each household individually and repeatedly. They can be successful in the sense that they stand on a neutral position between EA and APs, monitoring resettlement process and occasionally help APs in the process on their side, grasping APs' livelihood and trying to give them support corresponding to their living standard.

We have to note that almost all of the people consider and have the consensus that the project itself is necessary for development of the country in STDP case. This fact is the biggest preposition of the findings of this research. The question whether they are applicable to other cases where such a consensus is not made should be addressed in the future.

Finally, as an implication of this study, we note the danger of standardized 'vulnerable households', which one former RO also mentioned in the interview. For example, woman-headed households are often considered 'vulnerable', but the actual vulnerability of the household depends on her age or other family members. Rather than woman-headed 
household, for example, old husband and wife families should have been paid more attention as 'vulnerable people' because it is very difficult for them to rebuild a new house as in rural area people build their house on their own.

Through the interview to the staffs, we realized that the guideline on resettlement issues donor agencies set on their funding projects sometimes binds project staffs too much to think the situations flexibly. For example, in Safeguard Policy Statement of ADB describes: "The borrower/client will pay particular attention to the need of disadvantaged or vulnerable groups, especially those below the poverty line, the landless, the elderly, female headed households, women and children, Indigenous Peoples, and those without legal title to land" [9]. In the interviews to RDA staffs, when we asked what kind of people they think are the most vulnerable, some staffs answered as are exactly written in this statement. While noting the guidelines are not intended to bind them too much and the fact that they remember the guideline is very important, but we have to avoid the situation where project staffs think vulnerable people are only what were defined in the donor agency's guideline. Thinking further like "although ADB's guideline defines vulnerable people as XX, but in STDP especially these people in YY conditions are also vulnerable" is needed for relevant officers.

\section{ACKNOWLEDGMENT}

The author thanks his supervisors in the University of Tokyo, Asian Development Bank and our field study: Dr. Hideyuki Horii, Dr. Jayantha Perera and Dr. Karunathilake Kankanige.

\section{REFERENCES}

[1] T. T. Scudder, The Future of Large Dams: Dealing with Social, Environmental, Institutional and Political Costs, Sterling, VA: Taylor \& Francis, 2005.
[2] M. Cernea, "The risks and reconstruction model for resettling displaced populations," World development, vol. 25, no. 10, pp. 1569-1587, October 1997.

[3] M. M. Cernea, "For a new economics of resettlement: A sociological critique of the compensation principle", International Social Science Journal, vol. 55, no. 175, pp. 37-45, March 2003.

[4] Y. Kura, O. Joffre, B. Laplante, and B. Sengvilaykham, "Coping with resettlement: A livelihood adaptation analysis in the Mekong River basin," Land Use Policy, vol. 60, pp. 139-149, January 2017.

[5] A. Agrawal, "Local institutions and adaptation to climate change," in Social Dimensions of Climate Change: Equity and Vulnerability in a Warming World, R. Mearns, and A. Norton, Ed. Washington DC: World Bank, 2010, ch. 7.

[6] A. de Sherbinin, M. Castro, F. Gemenne, M. M. Cernea, S. Adamo, P. M. Fearnside, G. Krieger, S. Lahmani, A. Oliver-Smith, A. Pankhurst, T. Scudder, B. Singer, Y. Tan, G. Wannier, P.Boncour, C. Ehrhart, G. Hugo, B. Pandey, and G. Shi, "Preparing for resettlement associated with climate change," Science, vol. 334, no. 6055, pp. 456-457, October 2011.

[7] S. Morikawa, "Land acquisition, resettlement and resettlers' perception: The case of southern transport development project in Sri Lanka," Journal of Japan Society of Civil Engineers, Ser. F4 (Construction and Management), vol. 71, no. 4, pp. I_119-I_129, December 2015.

[8] S. Orr, J. Pittock, A. Chapagain, and D. Dumaresq, "Dams on the Mekong River: Lost fish protein and the implications for land and water resources," Global Environmental Change, vol. 22, no. 4, pp. 925-932, October 2012.

[9] Asian Development Bank, Safeguard Policy Statement, Manila, the Philippines: Asian Development Bank, 2009.

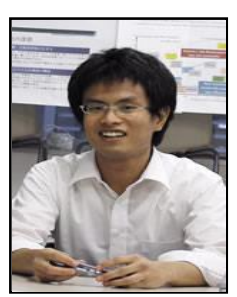

So Morikawa is an assistant professor at International Project Laboratory, Department of Civil Engineering, The University of Tokyo, Tokyo, Japan. He also serves as visiting researcher at SciREX Center, National Graduate Institute for Policy Studies, Tokyo, Japan. He got his MEng (Civil Engineering, 2011) and Ph.D (Public Administration, 2014) degrees both from the University of Tokyo. He has studied social impacts of infrastructure projects in developing countries since 2010 when he was intern at Asian Development Bank (ADB-UT Internship Program 2010). Currently, his research focus is relationship among technology, society and public policy in general, not limited to developing countries but also expanded to developed countries, where resources available for the government are becoming more and more limited. 